\title{
ENTRE A “GRANDE MÃE" E A "MUSA", A "LOUCA": EMBATE DE GÊNERO E ESTEREÓTIPOS NA CAMPANHA PUBLICITÁRIA “SNICKERS, VOCÊ NÃO É VOCÊ QUANDO ESTÁ COM FOME”
}

\author{
BETWEEN THE "GREAT MOTHER" AND THE "MUSE", THE \\ "CRAZY": CLASH OF GENDER ROLES AND STEREOTYPES IN THE \\ ADVERTISING CAMPAIGN "SNICKERS, YOU'RE NOT YOU WHEN \\ YOU'RE HUNGRY".
}

\author{
Dulce Elena Coelho Barros ${ }^{1}$ \\ Lorena Martins Pedroso Almeida ${ }^{2}$ \\ Sarah Mariana Longo Carrenho Cocato ${ }^{3}$
}

\begin{abstract}
RESUMO
Este artigo traz à memória dois dos mais expressivos estereótipos que acompanham a trajetória feminina junto à estrutura social, quais sejam, o da "grande mãe" e o da "musa". O empreendimento histórico-discursivo será, aqui, rememorado a partir da campanha publicitária da barra de chocolate Snickers, que tem como slogan "Você não é você quando está com fome". O enfoque se volta, mais vivamente, para duas das peças publicitárias videográficas, produzidas especificamente para serem veiculadas no Brasil, que se realizam com base numa perspectiva de embate de gênero masculino versus feminino. O anúncio publicitário "República" (2013) apresenta como protagonista a atriz Betty Faria e o anúncio publicitário "Vestiário" (2015) conta com a participação da atriz, não menos consagrada, Claudia Raia. Com base nessas duas materialidades eleitas enquanto corpus analítico, buscamos, em consonância com os pressupostos da Análise Crítica do Discurso (ACD) de Norman Fairclough, desvelar significados relativos ao cenário no qual entre a figura da "mãe" e da "musa" se interpõe a figura da "louca" que, aparentemente salvaguardada no simulacro da representação teatral, perpetua representações sociodiscursivas associadas ao pensamento patriarcal que identifica a mulher como naturalmente irritadiça, instável e psicologicamente patologizada.
\end{abstract}

PALAVRAS CHAVE: Análise Crítica do Discurso; Estereótipos de gênero; Identidade feminina.

\begin{abstract}
This article brings to mind two of the most expressive stereotypes that accompany the female trajectory through social structure, namely the "great mother" and the "muse". Here, this historical-discursive enterprise will be remembered from the advertising campaign for Snickers chocolate bar, which has the slogan "You are not you when you are hungry". The focus is on two of the video advertising pieces produced specifically to be aired in Brazil, which are based on a perspective of the clash of gender roles. The advertisement "Republic" (2013) features actor Betty Faria and the advertising "Locker Room" (2015) features the participation of no lesser actor,

\footnotetext{
${ }^{1}$ Doutora em Linguística pela Universidade de Brasília (UnB), mestre em Linguística e Língua Portuguesa pela Universidade Estadual Paulista "Júlio de Mesquita Filho" (UNESP), professora Associada B do Colegiado de Letras da UNESPAR - Campus de Paranaguá. Membro do corpo docente do Programa de Pós-Graduação em Letras da Universidade Estadual de Maringá (UEM), atuando na área de Estudos do Texto e do Discurso. Faz parte do Grupo Brasileiro de Estudos de Discurso, Pobreza e Identidades, integrado à REDLAD (Rede Latino Americana de Estudos do Discurso/ CNPq).

${ }^{2}$ Graduada em Letras, com habilitação em Língua Portuguesa e Literaturas Correspondentes, pela Universidade Estadual de Maringá (UEM). Assistente de Revisão de Texto da UNICESUMAR.

${ }^{3}$ Graduada em Letras, com habilitação em Língua Portuguesa e Literaturas Correspondentes, pela Universidade Estadual de Maringá (UEM). Faz parte da equipe de qualidade textual da UNICESUMAR.
} 
Claudia Raia. Based on these two materials chosen as analytical corpus, we seek, in consonance with the assumptions of Norman Fairclough's Critical Discourse Analysis (CDA), to unveil meanings related to the scenario in which the figure of the "mother" and the "muse" are disrupted by the figure of the "crazy" who, apparently safeguarded in the simulacrum of theatrical performance, perpetuates socio-discursive representations associated with patriarchal thinking that identifies women as naturally irritable, unstable and psychologically pathologized.

KEY WORDS: Critical Discourse Analysis; Female identity; Gender stereotypes.

\section{CONSIDERAÇÕES INICIAIS}

O presente artigo foi concebido após a inquietação das autoras diante da campanha publicitária da barra de chocolate Snickers, que tem como slogan "Você não é você quando está com fome". Como participantes do movimento feminista, repudiamos as representações estereotipadas que identificam a mulher como naturalmente irritadiça, instável e psicologicamente patologizada, principalmente, porque essas imagens são construídas a partir do imaginário patriarcal e de suas necessidades de perpetuação da dominação/hegemonia masculina sobre o corpo social feminino. Ao nos debruçarmos sobre duas peças videográficas da campanha, quais sejam, "República" (2013), que trazem como protagonista a atriz Bethy Faria, e "Vestiário" (2015), que apresenta como protagonista a atriz Claudia Raia, percebemos que as mesmas foram compostas retratando, respectivamente, os dois estereótipos sugeridos por C.G. Jung (1875-1961) que recaem sobre as mulheres: "a grande mãe" e "a musa".

As peças publicitárias foram produzidas num jogo de alternância de gênero. As atrizes, ao interpretarem um homem são corporificadas como mulheres e, devido à suposta fome que leva os personagens a consumirem o produto Snicker, revelam personalidades e atitudes comportamentais desestabilizadas das mesmas frente ao evento. Em ambos comerciais, imediatamente após comerem o produto anunciado, na figura de rapazes tranquilos e calmos, as personagens voltam "ao normal", reafirmando a mudança brusca de comportamento que, supostamente caracterizaria as mulheres. Compreendemos, a partir daí, que no entremeio dos dois pilares em que se sustentam as imagens, supostamente positivas e memoráveis, da "grande mãe" e da "musa" situa-se o arquétipo da "mulher louca".

Abordaremos as questões de gênero que atravessam os comerciais a partir da Análise Crítica do Discurso (ACD). Para tanto, nos apropriamos de aspectos teórico-metodológicos cunhados por Norman Fairclough (2001), conduzindo a análise que visa retratar e discutir criticamente os estereótipos de gênero que sustentam o "arquétipo de louca" nas peças publicitárias escolhidas para protagonizar este estudo.

\section{Análise Crítica do Discurso: ferramenta de combate aos estereótipos}

Para explicitar os sentidos socialmente desfavoráveis/nocivos à identidade feminina nos comerciais analisados, acionamos a Análise Crítica do Discurso (ACD). Postulada de modo consistente no final da década de 80, com a publicação dos livros "Language and power", de Norman Fairclough; "Language, power and ideology", de Ruth Wodak; e "Prejudice in discourse", de Teun van Dijk. A partir de um enfoque neomarxista, a ACD constituiu-se como alternativa às teorias de Análise do Discurso existentes destacando a interferência de fatores sociais na construção de significados, nas relações de poder, manipulação e dominação dos sujeitos sociais no uso da língua.

Desse modo, a ACD propõe um trabalho interdisciplinar de forma a alcançar uma compreensão mais completa de como a linguagem funciona, por exemplo, na constituição e transmissão do conbecimento [...] e no exercício do poder (WODAK, 2004, p. 236). No cerne da Análise Crítica do Discurso, portanto, 
situa-se a concepção de linguagem como prática social, com potencial para criar, corroborar ou negar sistemas de dominação, construir ou desconstruir identidades, estabelecer ou deslegitimar verdades.

A ACD ao relacionar as práticas discursivas ligadas às práticas sociais, e vice-versa, objetiva identificar e superar possíveis obstáculos de natureza discursiva que podem vir a interferir diretamente sobre a vida social dos sujeitos constituídos/subjetivados frente às práticas linguístico-discursivas que ecoam na sociedade.

O elemento crítico da ACD confere-lhe um propósito emancipatório que a caracteriza de forma contundente, posto que visa atuar socialmente, buscando interromper processos discriminatórios ou de dominação por meio da investigação dos discursos e promoção de uma consciência crítica das formas de atuação dos mesmos sobre as estruturas sociais. De acordo com Wodak (2004, p. 236), as teorias críticas conferem uma posição especial à ação humana. Conforme destaca a estudiosa, elas objetivam: a) a produção de conscientização e da emancipação; b) não apenas descrever e explicar, mas também expor um tipo particular de engano.

Para a pesquisadora, as teorias críticas pretendem despertar nos agentes (atores sociais) a consciência de que, com frequência, eles são enganados a respeito de suas próprias necessidades e interesses. Nesse sentido, a ACD empreende um "passo adiante" em relação às demais teorias de Análise do Discurso. Diríamos que esse viés discursivo não se limita a apontar para as formas de perpetuação do poder, para as práticas manipuladoras e discriminatórias, pois compreende que as mesmas podem ser transformadas por meio do contradiscurso. Nesse sentido, se os discursos recorrentes podem ser, por um lado, fator de perpetuação de práticas discursivas, por outro, podem, promover a libertação. Salta aos olhos o propósito emancipatório desse viés teóricoanalítico, sintetizado no chamado modelo tridimensional de análise do discurso cunhado pela análise de discurso britânica.

Nesse modelo, os eventos discursivos são vistos, a um só tempo, como: a) texto (prática linguística realizada por meio da produção de textos situados em contextos de produção); b) prática discursiva (discursos recorrentes em meio ao corpo social que carrega em si visões de mundo, conhecimentos, ideologias, relações de força e poder, entre outras dimensões que lhes configuram); c) prática social (o agir dos sujeitos nos espaços sociais a eles acessíveis).

De acordo com Ramalho e Resende (2004):

\begin{abstract}
São categorias da análise textual o vocabulário, a gramática, a coesão e a estrutura textual. [...]. $\mathrm{Na}$ análise das práticas discursivas, participam as atividades cognitivas de produção, distribuição e consumo do texto. Analisam-se também as categorias força, coerência, e intertextualidade. [...]. A análise da prática social está relacionada aos aspectos ideológicos e hegemônicos na instância discursiva analisada. Na categoria ideologia, [observamos] os sentidos das palavras, as pressuposições, as metáforas, o estilo. Na categoria hegemonia, observam-se as orientações da prática social, que podem ser orientações econômicas, políticas, ideológicas e culturais (p. 188).
\end{abstract}

O modelo tridimensional de Fairclough pressupõe que nenhuma dessas dimensões seja preterida ou supervalorizada, pois influem umas nas outras. Observa-se, portanto, a centralidade nas análises discursivas. Em termos metodológicos, tais dimensões traduzem-se na descrição do corpus de análise (dimensão textual), na interpretação dos fatos discursivos (dimensão discursiva) e na posterior explanação crítica sobre as relações sociais estabelecidas (dimensão social).

A perspectiva funcionalista de estudos da linguagem sugerida por Michael Halliday passa a ser central na ACD, a qual propõe o resgate das três macrofunções da linguagem apontadas pelo consagrado pesquisador, a saber, as funções ideacional, interpessoal e textual.

A Linguística Sistêmico Funcional (LSF) é uma teoria que entende a linguagem como um fenômeno social e não individual. Para Halliday (1994), todo texto é funcional, ou seja, 
desempenha uma série de funções. Com isso, para o autor, cada variável contextual está relacionada a uma metafunção, sendo elas: a ideacional, a interpessoal e a textual.

Sobre as metafunções enunciadas por Halliday, Barros (2010, p.4) destaca que:

Desempenham papel fundamental na teoria e método de análise sistêmico-funcional justamente por permitir entender a estrutura linguística como elemento que engloba: 1a nossa maneira de ver as coisas ou vivenciar o mundo que nos cerca (significados ideacionais); 2- as formas de estabelecimento e manutenção das relações sociais ou interpessoais (significados interpessoais); 3- a nossa capacidade de construir textos e reconhecê-los como unidades significativas (significados textuais).

A metafunção interpessoal estabelecida por Halliday é dividida por Fairclough em duas, a função identitária e a função relacional. Entende-se por função identitária a maneira com que as características dos sujeitos são construídas e reverberadas pelos discursos. A função relacional diz respeito à forma com que os sujeitos e suas identidades se relacionam socialmente, o que compreende imbricadas relações de poder. Tais conceitos são muito bem definidos por Resende e Ramalho (2004, p. 189), que se baseiam nos escritos de Fairclough:

$\mathrm{Na}$ função ideacional, o discurso contribui para a construção de sistemas de conhecimento e crença (ideologias), por meio da representação do mundo 'como o mundo é' para o locutor; na identitária, o discurso contribui para a constituição ativa de auto-identidades e de identidades coletivas; na relacional, o discurso contribui para a constituição de relações sociais.

As funções relacionais e identitária de Fairclough passam a compor os chamados por ele de significados identificacionais do discurso. Os gestos analíticos, aqui realizados, voltando-se para a representação identitária do sujeito "mulher". Desse modo, devem realizar-se à luz desse viés teórico-metodológico, posto que os estereótipos femininos engendrados pelos comerciais, quais sejam, o de indivíduo emocionalmente desestabilizado, facilmente irritável, histérica e explosiva, criando-se, assim, as condições ideais para a consolidação do arquétipo de "louca" a ela atribuído, via discursos recorrentes e difundidos junto aos meios de comunicação de massa. Nesse passo, compreendemos que as determinações identitárias depreciativas que recaem sobre a mulher advêm das relações de dominação e sujeição pautadas, por sua vez, no pensamento patriarcal e consolidadas nas práticas discursivas hegemônicas.

\section{Publicidade e significados identificacionais: porque mulheres e não monstros?}

Os termos publicidade e propaganda são comumente utilizados com o mesmo sentido. No entanto, estudiosos que se debruçam sobre os conceitos admitem haver diferenças fundamentais neles inscritos.

Segundo Medeiros (2008, p. 43), a propaganda pode ser entendida como a divulgação de uma mensagem buscando influenciar opiniões ou obter adesão para uma ideia ou doutrina. Visa, pois, objetivos políticos e não comerciais e pode ter duplo papel na sociedade: manter o status quo ou implantar mudancas sociais.

Conforme destaca Medeiros (2008), em contrapartida, a publicidade pretende divulgar um produto, um serviço, uma marca, com fins comerciais (p. 43). Seu objetivo principal seria o de convencer, consciente ou inconscientemente, um determinado público a adquirir certo produto. Para tanto, a mensagem publicitária se utiliza de recursos estilísticos, semânticos e lexicais, que dependem do canal em que serão veiculadas - televisão, rádio, revistas, jornais, outdoors etc. COSTA (2006, p. 2) também parte do princípio de que a publicidade não tenha, deliberadamente, fins políticos, apesar de sustentar uma argumentação icônico-linguística que, por seu caráter discursivo, provoca reverberações no plano social. No entanto, quando se pensa nos efeitos das práticas linguístico- 
discursivas, no seu caráter acional sobre a reprodução de um conjunto de ideias determinantes e mantenedoras de estereótipos, preconceitos e, por sua vez, consolidadoras de arquétipos, é desejável também que os elementos composicionais dos comerciais sejam interpretados à luz de uma perspectiva crítica.

As duas peças publicitárias selecionadas para este estudo se inscrevem no gênero anúncio vídeo-gráfico, tendo sido veiculadas pela televisão e internet nos anos de 2013 (República) e 2015 (Vestiário). A versão mais recente do comercial, com Claudia Raia, retoma o mesmo formato daquele utilizado em 2013, com Bethy Faria. Durante as campanhas publicitárias dos produtos Snickers, o modelo composicional dos comerciais foi, inclusive, utilizado em mais de oitenta países com versões diferentes. No entanto, em outros países, o recurso utilizado para demonstrar que pessoas com fome podem, eventualmente, digamos, apresentar mudança comportamental é substituído, por exemplo, por um personagem "monstro", fazendo às vezes do personagem mulher. Questionamos, neste limiar, porque mulheres e não monstros como recurso semiótico de representação da aberração?

Segundo Costa (2006), é através das campanhas publicitárias que as marcas engendram para si uma atmosfera específica, uma mitologia, ou seja, uma representação idealizada de estados de coisas advindas do imaginário coletivo, que exerce a função de espelhar e validar a identidade do público-alvo:

\begin{abstract}
Os textos publicitários apresentam, por conseguinte, uma versão bem particular da realidade, talhada de acordo com as presumíveis atitudes e valores do público-alvo. É seu papel preencher a carência de identidade de cada leitor/potencial consumidor, a necessidade que cada um tem de aderir a valores que confirmem os seus próprios e lhe permitam compreender o mundo e seu lugar nele (p. 2).
\end{abstract}

Identificado com a publicidade e seu objeto de venda, o consumidor é induzido à compra pela sensação de que o produto fora "feito para ele". As mitologias de marca, portanto, constituem-se como valor central da publicidade, e, como tal, são muitas as maneiras de construílas. Todas, no entanto, acionam com grande expressão as funções identitárias e relacionais da linguagem e, por conseguinte, os significados identificacionais do discurso.

Nas peças publicitárias analisadas, o mito de marca é gerado pela recorrência a arquétipos, construções propostas por Carl Gustav Jung, que correspondem às idéias comuns partilhadas entre todas as pessoas, existentes no inconsciente e funcionando como instintos moldadores do comportamento desde a origem da espécie humana (PETRY; SILVA, 2004). Os arquétipos são essencialmente representativos no que diz respeito às questões de gênero, posto que, enquanto construto social, o gênero pode ser definido como conjunto arquetípico de características associado e imposto aos sexos. Acionando arquétipos, a publicidade atua como mecanismo ideológico na manutenção das formas naturalizadas daquilo que se entende por masculino e feminino.

São duas as imagens básicas de arquétipos femininos propostas por Jung, descritas por Costa (2006, p. 2): a da Grande Mãe - que mostra a mulher como eterno ventre, eterna provedora -, e a da Musa, que se traduz pela noção da mulher fascinante, sedutora, fatal.

Entendemos que, ao se estabelecer um paralelo entre os comerciais da Snickers, a saber, República, com Betty Faria e Vestiário com Cláudia Raia, medeiam essas duas práticas um terceiro arquétipo, o da "mulher louca". O que se sustenta na observação de uma tendência, no interior de algumas das práticas linguístico-discursivas brasileiras, representar-se a mulher como emocionalmente desestabilizada, facilmente irritável, histérica e explosiva. Vejamos que serve de mote para a composição de ambos comerciais a mudança brusca de comportamento em que "você não é você" se justifica na alternância na identidade de gênero masculino versus feminino. Eis que, subjacente a essa ideia surge, personificada em um corpo feminino, representando a desconfiguração tanto do corpo quanto da mente masculina, a figura da mulher, a "grande mãe", 
de um lado, e a "musa", de outro, perfeitamente reconhecíveis em seus papeis, no entanto, causando o estranhamento desejado.

\section{Monstros e aberrações não: a "mulher louca"}

Ao longo da história, as mulheres foram inferiorizadas e desqualificadas em diversos âmbitos da vida, tratadas como o "sexo frágil". Isso, infelizmente, mantém-se até os dias atuais: as mídias, em geral, baseiam-se em ideais patriarcais para o comportamento dos gêneros, e nossos sentidos e identidades são construídos, principalmente, por meio de discursos midiáticos. Abordemos e discutamos, portanto, o discurso hegemônico e machista que representa as mulheres como emocionalmente desestabilizadas. Ressaltemos que essa prática se realiza em oposição aos preceitos emocionais supostamente reservados para os homens, que costumam ser representados discursivamente como sujeitos equilibrados, centrados e racionais.

A difusão desses embates discursivos nos quais pesam sobre a identidade de gênero feminino valores e visões enfraquecedoras e, via de regra, depositários de ideais que depõem sobre o corpo social feminino frente ao masculino, funciona como ferramenta de manutenção do status quo útil, sobremaneira, à ordem social vigente. Urge, portanto, que enfatizemos o papel desempenhado pela mídia frente aos processos de difusão e de naturalização desses discursos via gênero publicidade - uma propaganda da barra de chocolate Snickers -.

Segundo Fabrício (2004), é comum a localização do universo feminino no território do descontrole, da patologia e do comportamento obsessivo. Tal tendência ganhou corpo no período iluminista, em que a ciência, ainda cega quanto aos atravessamentos ideológicos que recaem sobre si, produziu diversos estudos equivocados que deram respaldo a tal movimento. $O$ pensamento da época mostrava-se ambíguo: dizia-se que homens e mulheres eram iguais, ao mesmo tempo em que, por uma necessidade de explicar a evidente disparidade comportamental e social entre os sexos, afirmava-se que:

\footnotetext{
a "natureza" feminina imputava a estas traços inerentes de certa irracionalidade, passionalidade e dependência emocional que as tornariam incapacitadas de atuar no domínio público da vida política, econômica, científica e intelectual, atributos identitários do mito da masculinidade hegemônica (FABRÍCIO, 2004).
}

Assim, o emocional feminino se mostrava entrave para que as mulheres conseguissem realizar atividades mais complexas que cuidar da casa e dos filhos. Tal discurso foi propalado e difundido ao longo dos séculos, e, ainda nos dias atuais, a imagem de mulheres descontroladas emocionalmente se propaga, naturalizando-se. A própria produção literária valeu-se, no passado, das representações de mulheres loucas. Segundo Schwantes (2005), tais representações fazem com que questionemos as ideias a respeito da feminilidade. Como afirma a autora:

\footnotetext{
Loucas não se comportam dentro do padrão de decência, pudor, inocência e doçura que é socialmente esperado de pessoas do sexo feminino, e assim as personagens [...] são, freqüentemente, violentas, lascivas, descontroladas. Seu comportamento é, então, explicado nos termos de sua patologia - medida necessária para que nossas certezas sobre a natureza das mulheres permaneçam intactas (SCHWANTES, 2005, p. 1).
}

As mulheres que não representam os arquétipos da Grande Mãe e/ou da Musa não seriam, então, passíveis de serem compreendidas e vislumbradas à altura daquilo que conhecíamos como "feminino". De tal modo, o comportamento delas só poderia ser visto como doentio. No entanto, nem sempre esse discurso se mostrava ou repercutia de modo negativo no interior das práticas sociolinguísticas, como nos sugere Schwantes (2005, p. 3). Autoras dos séculos passados dão espaço às personagens mulheres e loucas para explicitar a injustiça e a 
irracionalidade de uma sociedade que divide e hierarquiza seus membros de acordo com seu gênero (e sua etnia, podemos acrescentar).

Sendo assim, é perceptível que nas peças publicitárias em foco o monstro/aberração é substituído pelas mulheres que, mesmo desempenhando os papeis que arriscamos chamar de "grande mãe" e de "musa", causam o estranhamento/humor relativamente à quebra padrões de previamente estabelecidos. Vejamos a seguir que as personagens corporificadas como mulheres nos comerciais tomam os turnos de fala enquanto personagens masculinos e não femininos. Como tal se apropriam de um linguajar masculinizado e sexista. A ordem do discurso publicitário, em condições propícias ao intento comercial, muitas vezes, difunde ideologias e valores culturais, políticos e sociais que enfraquecem identidades de gênero.

\section{Nem mãe, nem Musa: "louca"}

As peças publicitárias analisadas são componentes centrais da campanha "Snickers: você não é você quando está com fome", produzidas pela agência Alma-BBDO. O produto divulgado, a barra de chocolate Snickers ${ }^{\circledR}$, é um dos carros chefe da empresa alimentícia americana Mars Incorporated, que também é dona de outras marcas importantes como M\&'M's, Twix, Uncle Ben's, Pedigree e Whiskas.

A campanha compreende anúncios, pôsteres e embalagens especiais que, por meio das diferentes semioses engendradas, retratam comportamentos adversos que a fome supostamente provocaria, buscando suscitar no consumidor um efeito humorístico e de estranhamento. Nas novas embalagens do produto, lê-se, no lugar do logotipo usual, adjetivos como irritados(a), lesado(a), confuso(a), dentre outros, que representariam os principais sintomas eventualmente advindos do fato de se estar há muito tempo sem comer. O título da campanha, "Você não é você quando está com fome", é o slogan tradicional do produto, servindo de mote aos anúncios videográficos que foram veiculados pela televisão e internet. Dois deles são descritos e analisados a seguir:

O primeiro comercial, República - Snickers (2013) com Betty Faria, inicia-se com a imagem de três jovens no ambiente de uma república universitária; dois deles jogam videogame, enquanto o terceiro se exercita. Em segundo plano, é possível ver a personagem interpretada por Betty Faria que, ao fechar a geladeira de modo irritado, diz: "Maravilha, esvaziar a geladeira os vagabundos sabem, agora fazer compras...". Um dos jovens que joga videogame exclama: "Depois a gente faz, velho", ao que a personagem de Betty Faria responde, de forma irônica, enquanto joga um objeto na cabeça do colega: "Depois? Depois, a gente lava, depois, a gente limpa, depois, a gente espera o 'trouxa' fazer tudo". Neste momento, o rapaz que se exercitava aproxima-se de Betty Faria e oferece-lhe a barra de chocolate, dizendo: "Na boa, Léo, come um Snickers". Betty Faria/Léo pergunta-lhe: "Por quê??", e o colega responde: "Porque 'cê' fica insuportável quando 'tá' com fome". A personagem de Faria morde o chocolate e, após a câmera voltar-se ao colega que lhe pergunta: "Melhor?", vemos o novo intérprete da personagem: um jovem ator que responde, com um sorriso de alívio, "Melhor". A sequência final, contendo a apresentação do produto e locução do emblemático slogan, repete-se.

O segundo comercial, Vestiário - Snickers (2015) com Cláudia Raia, inicia-se pela imagem em aproximação de um vestiário masculino, em que se vê diversos homens, alguns envoltos em toalhas, trocando de roupas e conversando de modo descontraído, quando a câmera muda de posição e focaliza a atriz Cláudia Raia. Ela está de costas, procurando um objeto, e se vira abruptamente para dois rapazes que conversam entre si. Utilizando linguagem coloquial, em tom masculinizado, diz: "Aí, seus pela-saco, quem foi que pegou o meu desodorante?". Ao final de sua fala, a câmera se vira para os dois rapazes, e um deles lhe responde: "Ih, se liga! 'Cề' acha mesmo que alguém aqui quer ficar com o cheirinho igual ao seu?”, os dois riem, e ele completa: 
"Ah, tá bom!". A câmera se volta para Cláudia Raia, que imita, forçosamente, uma risada e diz: "Boa! A sua irmã não reclama do cheiro! Pelo contrário...".

O rapaz que, no turno de fala anterior havia interpelado a personagem representada por Raia, mostra-se ofendido, mas, antes que consiga dizer qualquer coisa, um terceiro rapaz entra em cena, dizendo: "Ei, ei, Rafa! Come um Snickers."; a atriz, vestida com roupas femininas, desempenhando, porém, papel masculino, responde com uma indagação: "Por quê?"; e o rapaz responde: "Porque 'cê' dá muito chilique quando 'tá' com fome."; durante o diálogo, a câmera se alterna entre o terceiro rapaz e Raia / Rafa, que, ao final da cena, morde um pedaço da barra de chocolate. A câmera focaliza o terceiro garoto, que lhe pergunta: "Melhor?". Ao fim da indagação, a câmera volta para onde, anteriormente, estava posicionada Cláudia Raia, mas, naquele momento, surge "o verdadeiro" Rafa, interpretado por um jovem ator, que responde, demonstrando serenidade e mastigando: "Melhor!". Os quatro rapazes sorriem e o clima se mostra descontraído.

Nos dois comerciais, a frase/slogan "Você não é você quando está com fome" aparece na tela e é narrada em off. A composição do chocolate - uma barra com amendoim e caramelo, coberta por chocolate - surge e a mesma narração diz "Snickers é uma barra de chocolate, amendoim e caramelo, que mata a sua fome". Os comerciais se encerram com a marca do chocolate - Snickers - e a frase de impacto "Mata sua fome".

A repetição da mesma estrutura cria um padrão narrativo aos anúncios: nos dois contextos, os personagens masculinos são, de tal modo, alterados pela fome que, literalmente, já não se parecem consigo mesmos. Se lidos de forma ingênua, poderia se considerar que o humor é produzido pelo modo inusitado com que Betty Faria e Claudia Raia, atrizes de renome, são retratadas em contextos tão alheios às suas realidades - uma república universitária e um vestiário masculino -, ou pela mera quebra de expectativa provocada pela troca das atrizes por atores, referendando outra troca, qual seja, a de comportamento.

O humor, no entanto, constitui-se pela adesão da propaganda aos discursos dominantes e acríticos sobre gênero. Significativamente, o recurso de criação do padrão narrativo apontado é a escolha de mulheres para interpretar os personagens masculinos em seus momentos de irritabilidade, mas não de descontrole ou confusão mental, sugeridos nas embalagens. Descontrole, desequilíbrio e confusão mental devem ser interpretados como características eminentemente femininas, advindas do senso comum, para que se cumpra a função apelativa da linguagem publicitária e para que se provoque o efeito desejado, a saber, o riso. Tal recurso é apoiado e engendrado por diversos aspectos linguísticos e visuais dos anúncios.

Ambos os vídeos são ambientados em espaços essencialmente masculinos: a república universitária e o vestiário são concebidos como ambientes em que o homem congrega com seus iguais e cultiva/reproduz comportamentos estereotipados considerados prototípicos da masculinidade. A cena inicial do segundo anúncio (Raia/Rafa) apresenta-nos o espaço em que se dará a breve narrativa pelo enfoque direto de um grupo numeroso de homens, vestindo-se e interagindo de modo descontraído. No segundo anúncio (Faria/Léo), a câmera captura apenas os rapazes, que jogam videogame e praticam musculação. Instaura-se, portanto, que a normalidade correspondente a esses espaços é a da ocupação masculina.

Nesses contextos, a figura feminina é o elemento desviante, inesperado, problemático e assim deve ser entendido pelo consumidor para que seja promovida a função persuasivoargumentativa das peças publicitárias e, consequentemente, a venda do produto. Nesse ínterim, fortalecem-se visões de mundo e práticas discriminatórias que incidem sobre o corpo social feminino. No primeiro comercial configura-se a intromissão feminina na figura da "grande mãe" que busca por ordem no ambiente doméstico, privado e comunitário. No segundo essa intromissão se manifesta na figura da "musa", bela e sedutora. Neste movimento analítico, percebemos também que, no que se refere à questão da sexualidade, o diálogo travado no 
vestiário fortalece e reproduz a ideia da "mulher presa" e do "homem predador", como se vê em: "Boa! A sua irmã não reclama do cheiro! Pelo contrário...".

Observa-se que a escolha dos figurinos contrasta com os ambientes em que as cenas se desenvolvem. Tanto Cláudia Raia quanto Betty Faria aparecem maquiadas e usam vestidos luxuosos, festivos, em tom vivo de azul, o mesmo tom que domina a embalagem do produto. Valendo-nos do recurso da intertextualidade, aproveitamos para reafirmar, aqui, que os mil tons de azul são masculinos.

No entanto, por um lado, o ambiente público da "academia de esportes", frequentado, principalmente, para a obtenção do corpo esbelto e esteticamente belo, faz com que se reconheça em Raia a "musa". Cumpre salientar que atriz Claudia Raia, famosa por sua beleza e talento, aparenta ter a mesma idade e complexão física dos atores com os quais está contracenando. Por outro lado, o ambiente familiar da "república" e o diálogo travado pelos personagens em torno de afazeres domésticos fazem com que se reconheça em Faria a "grande mãe", mesmo porque, a atriz aparenta ter mais idade do que os atores com os quais está contracenando e porque delega tarefas vistas como essencialmente femininas. Trava-se entre eles um diálogo também representativo das práticas linguageiras comuns às mulheres mães ao buscarem delegar tarefas domésticas aos filhos homens.

Os tons de azul dos figurinos, ícones culturais de masculinidade, associam as atrizes aos atores que interpretam os mesmos personagens: elas em suas performances/representações femininas, desequilibradas, mentalmente confusas pela fome, como sugerem as embalagens do produto; eles em suas atuações/representações prototípicas masculinas, plácidos, equilibrados e racionais, sendo eles que na sequência da performance teatrilizada vêm a consumir o produto com deleite e prazer.

As imagens selecionadas revelam os cenários em que os pares contracenam:
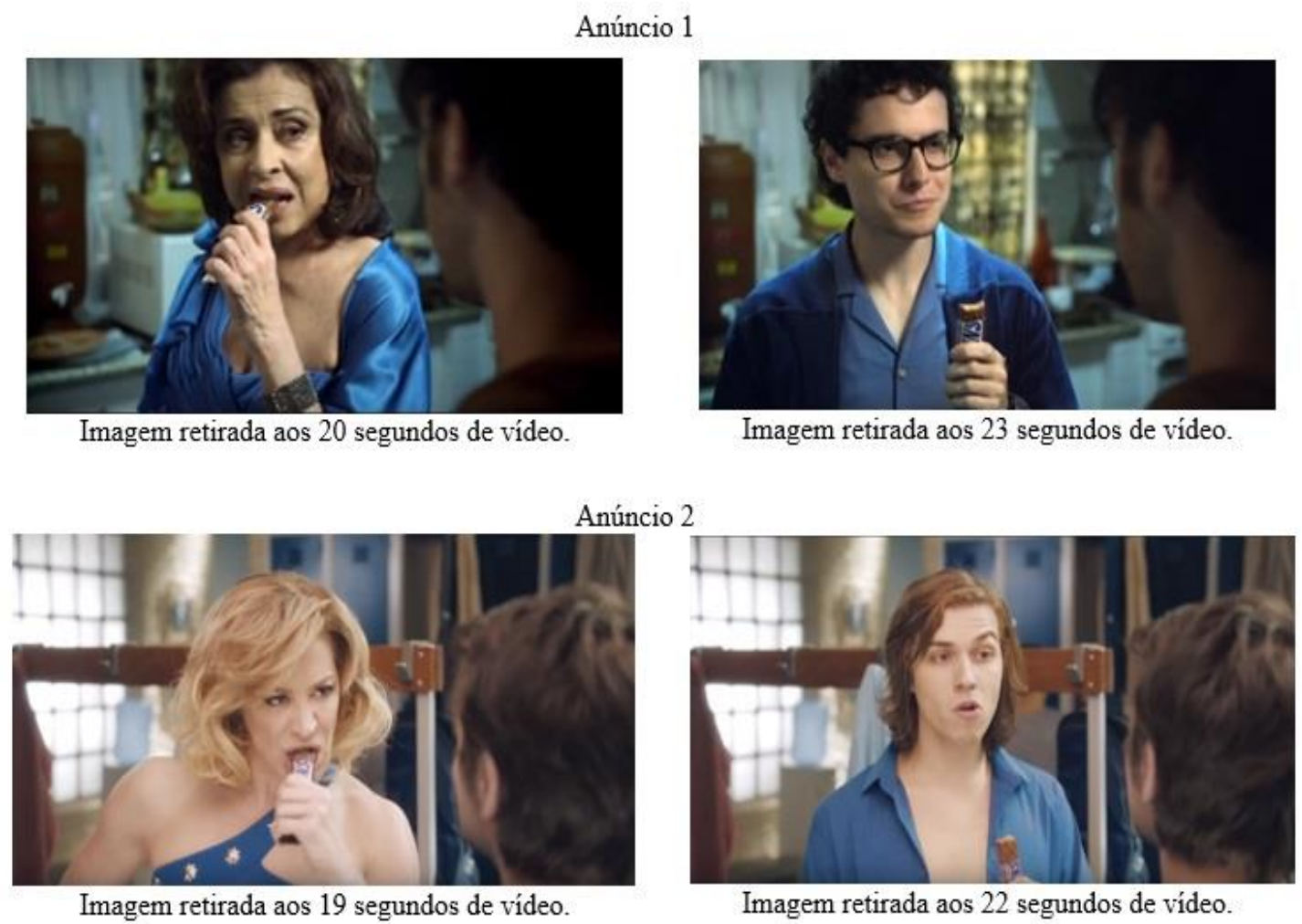

Rememorando a função precípua do gênero anúncio publicitário, lembremo-nos de seu objetivo comercial: a venda do produto pressupõe a criação de um mito de marca elaborado de 
acordo com o consumidor alvo, no qual ele poderá se reconhecer identitariamente. Nesse ponto, notamos, claramente, qual é o público alvo dos anúncios analisados: a promoção/ a difusão do produto se faz dirigindo-se ao homem jovem e heterossexual. Os ambientes retratados, que, inclusive, estabelecem os critérios de normalidade ou anormalidade à narrativa, são masculinos, bem como são os atores que aparecem portando ou consumindo o produto por maior tempo.

Dessa forma, para que o jovem homem heterossexual se reconheça na marca anunciada, a publicidade aciona a função identitária da linguagem, como descrita por Fairclough. Posto que a concepção binária dos gêneros estabelece as categorias de masculino e feminino como opostos e excludentes. O anúncio é propalado sustentando a ideia de que a identidade masculina se estabelece pela oposição aos caracteres femininos: o homem, consumidor alvo, é ou deve ser aquilo que a mulher não é. É no embate dos gêneros que ecoam o tradicionalismo, o conservadorismo e a luta pela preservação das estruturas de poder hegemônicas.

Nos dois anúncios, Betty Faria e Cláudia Raia são representadas como indivíduos insatisfeitos e incomodados com as circunstâncias. Na primeira peça, a personagem interpretada por Betty Faria preocupa-se com os afazeres domésticos, queixando-se de que se encarrega deles sozinha; os colegas, diante disso, respondem com frases como: "Depois a gente faz, velho", demonstrando despreocupação. Evidencia-se, pois, o contraste entre aquele que reclama, impõe, incomoda, exagera (domínio feminino) e aquele que suporta, ignora, racionaliza (domínio masculino).

$\mathrm{Na}$ segunda peça publicitária, a personagem questiona os colegas a respeito de quem, por ventura, havia se apropriado de seu desodorante; a pergunta, no entanto, é tomada pelos colegas como necessariamente indevida, incabível e produtora de certo descrédito, cujo efeito é de natureza pejorativa: "Ih, se liga! 'Cê' acha mesmo que alguém aqui quer ficar com o cheirinho igual ao seu?", responde um dos rapazes, implicando que não chega a considerar a colocação do personagem feminino como possível. É significativo o fato de que é o consumo do produto que transporta a personagem do domínio feminino ao domínio masculino. O discurso subjacente, direcionado ao público alvo, é o de que, para que se tenha acesso à masculinidade, a qual se deve cultivar e reafirmar, se faz necessário consumir o produto. Nas cenas finais de ambos os anúncios, em que um dos personagens oferece a barra de chocolate às atrizes, questiona-se: "Por quê?", ao que os parceiros de cena respondem: "Porque 'cê' dá muito chilique quando 'tá' com fome" (anúncio 1); "Porque 'cê' fica insuportável quando 'tá' com fome” (anúncio 2), "Chilique" e "insuportável", vocábulos tradicionalmente associados ao comportamento feminino, são marcadores identitários da mulher nos anúncios. Quando a personagem deixa de "dar chilique" ou deixa de ser "insuportável", deixa também de ser interpretada por uma mulher. Havendo, portanto, a transposição de sexo, imediatamente, realiza-se a transposição de personalidade. Sendo assim, as condições ideais para a obtenção do êxito discursivo são preenchidas.

\section{A cena termina: resta o silêncio da insanidade}

Nas materialidades postas em análise neste artigo, percebe-se que as cenas enunciativas se desenvolvem em consonância com as metafunções relacional e identitária da linguagem. Os jogos de alternância que se estabelecem entre os personagens incidem diretamente sobre os significados identificacionais do discurso engendrado. Esse jogo lúdico, aparentemente ingênuo, que busca despertar o riso, contribui para a reprodução de sistemas hegemônicos de dominação, bem como para a perpetuação da ordem social vigente. Entendemos, a partir de Fairclough, que a função identitária da linguagem atua em consonância com a função relacional. Isso significa que a representação discursiva da identidade feminina como "irracional" ou "louca" advém de determinações sociais de natureza opositiva. Estabelecem-se, então, os pares identitários polarizados: "homem/mulher", "racional/irracional", "equilibrado/desequilibrada", "estabilizado/desestabilizada", "saudável/louca", dentre outros que daí pode-se inferir. 
A cena é finalizada, mas no eco contundente dessas polarizações retumbam relações de poder desejáveis, contornos ideológicos forjados, lutas hegemônicas que subjugam, oprimem e determinam papeis, não menos desejáveis, para o corpo social feminino, qual seja, o de "musa" ou o de "grande mãe". Àquelas que ousem subverter o estado de coisas, a ordem vigente, questionar estruturas patriarcais, resta-lhes o rótulo, advindo do discurso da patologia comportamental feminina, qual seja, o de "louca". Patologizadas, silenciadas, enclausuradas, enfim, impossibilitadas de modificar o status quo.

\section{REFERÊNCIAS}

BARROS, D. E. C. Teoria social do discurso e gramática funcional: uma relação desejável. Anais do $5^{\circ}$ Encontro do Grupo de Estudos de Linguagem do Centro-Oeste. Dourados, p. 1-15, setembro, 2010. COSTA, I. Gênero e preconceito: a mulher na/pela publicidade. Anais do VII Seminário Internacional Fazendo Gênero, 2006, Florianópolis. Florianópolis: Mulheres, v. 1, 2006.

COSTA, L. P. A. ADC faircloughiana: concepções e reflexões. Linguagem, São Carlos, ed. 20, out./dez. 2012.2 Disponível em: http://www.letras.ufscar.br/linguasagem/edicao20/ensaios/003.pdf. Acesso em 30 nov. 2018.

FABRÍCIO, B. F. Mulheres emocionalmente descontroladas: identidades generificadas na mídia contemporânea. Delta, São Paulo, v. 20, n. 2, dez. 2004. Disponível em: http://www.scielo.br/scielo.php?script=sci arttext\&pid=S0102-44502004000200003. Acesso em 28 nov. 2018.

FAIRCLOUGH, N. Discurso e mudança social. Brasília: Editora UNB, 2001.

HALLIDAY, M. A. K. An Introduction to Functional Grammar. Hodder Education, 1994.

MEDEIROS, A. G. da C. L. O gênero textual propaganda: descrição e uso em sala de aula. Dissertação (Mestrado em Linguística) - Programa de Pós-Graduação em Letras, Universidade Federal de Juiz de Fora, Juiz de Fora, 2008.

PETRY, H.; SILVA, R. Del Vechio. Os arquétipos nas propagandas de revistas femininas. Anais do XXVII Congresso Brasileiro de Ciências da Comunicação, Porto Alegre, 2004. Disponível em: http://www.nomads.usp.br/documentos/textos/modo.

RESENDE, V. de M.; RAMALHO, V. C. V. Análise do discurso crítica, do modelo tridimensional à articulação entre práticas: implicações teórico-metodológicas. Linguagem em Discurso, Santa Catarina, v. 5, n. 1, p. 185-207, jul./dez. 2004. Disponível em: http://linguagem.unisul.br/paginas/ensino/pos/linguagem/linguagem-em-

discurso/0501/050109.pdf. Acesso em 30 nov. 2018.

SCHWANTES, C. A voz da louca, a voz da outra. Labrys - Revista de Estudos Feministas, Brasília, v. $\quad 2005.2$ Disponível em: http://www.repositorio.unb.br/bitstream/10482/3737/4/ARTIGO VozdaLouca.pdf . Acesso em 03 nov. 2018.

WODACK, R. Do que trata a ACD - Um resumo de sua história, conceitos importantes e seus desenvolvimentos. Linguagem em Discurso, Santa Catarina, v. 4, n. esp., p. 223-243, 2004.

Disponível em: http://www.portaldeperiodicos.unisul.br/index.php/Linguagem Discurso/article/view/297/31 3. Acesso em 30 nov. 2018. 
Submetido em 05/11/2018 Aceito em 11/04/2019

Publicado em 02/08/2019 